\title{
Injuries in Iran Futsal National Teams: A Comparative Study of Incidence and Characteristics
}

\author{
Hooman Angoorani ${ }^{1}$; Zohreh Haratian ${ }^{1, *}$; Ali Mazaherinezhad ${ }^{2}$; Shima Younespour ${ }^{3}$ \\ ${ }^{1}$ Department of Sports and Exercise Medicine, Hazrat Rasool-e-Akram Hospital, Iran University of Medical Sciences, Tehran, IR Iran \\ 2 Minimally Invasive Surgery Research Center, Iran University of Medical Sciences, Tehran, IR Iran \\ 3 Department of Epidemiology and Biostatistics, School of Public Health, Tehran University of Medical Sciences, Tehran, IR Iran \\ ${ }^{*}$ Corresponding author: Zohreh Haratian, Department of Sports and Exercise Medicine, Hazrat Rasool-e-Akram Hospital, Iran University of Medical Sciences, Tehran, IR Iran. Tel: +98- \\ 2164352446, Fax: +98-2166509108, E-mail:dr_haratian@yahoo.com
}

Received: September 29, 2013; Accepted: March 25, 2014

\begin{abstract}
Background: Futsal is a growing sport with lots of fans in many countries including Iran, but there are few papers in the literature which report injuries in top level futsal.

Objectives: The aim of this study is to record and analyze the incidence and characteristics of injuries in Iran futsal national teams from March 2011 to September 2012.

Patients and Methods: 55 Iranian national futsal players participated in this prospective cohort study. Before entering the study, all players took part in Pre-Competition Medical Assessment (PCMA) in accordance with FIFA protocol. Team physicians recorded the injuries throughout the match and trainings in a special form which was designed for this purpose. Finally, data analysis was done with the SPSS software.

Results: The total exposure time for all players was 24326 hours (21138 hours during training and 3188 hours during matches). During the study period, 32 of the 55 national players ( $58.2 \%$ ) incurred 54 injuries (incidence rate $=2.22$ injuries per 1000 players-hours). The incidence rate of injury in female players was significantly higher than male players $(\mathrm{P}=0.001)$. The majority of injuries $(85.2 \%)$ were located on the lower extremities. The ankle was the most frequent injury location (40.7\%) and sprain was the most frequent type of injury.

Conclusions: Injuries are common among futsal players and female players are more prone to injuries than male players. The ankle is the most frequent site and sprain is the most frequent type of injury among futsal players.
\end{abstract}

Keywords:Incidence; Injuries; Soccer

\section{Background}

Futsal is a small-sided indoor version of football with different rules (1). Popularity of futsal in different communities is growing and more than one million official futsal players have already been registered by national federations worldwide. Although a few efforts have been done to run research studies on injuries and medical complaints of futsal players (2-5), these studies continue to lag behind the progress of the sport (6-14).SchmiklisL et al.(2), showed that futsal is among the top ten injury-prone sports with an incidence rate of 55.2 injuries per 10000 hours of sports participation (95\% CI: 42.7 to 71.3). This shows that the incidence rate of injury among futsal players is almost 2.7 times more than footballers who had an injury rate of 20.3 injuries per 10000 hours of sports activity (95\% CI 18.4 to 22.4). The higher prevalence of injury might be due to the differences in age and physiological demands of the two groups. Jung and his colleague (4) studied the injury characteristics in top level international futsal tournaments and reported an incidence rate of 195.6 injuries per 1000 player hours (95\% CI 165.8 to 225.6) and 130.4 injuries per 1000 player matches ( $95 \%$ CI 110.5 to 150.3 ). More than one third of the injuries were reported during non-contact activities and the majority of injuries occurred in the lower extremity, head and neck, upper extremity and trunk respectively. On basis of this study, it was suggested that the location of injuries might be similar among football and futsal players, although the rate of non-contact injuries in futsal is more than football. In order to provide more information about the pattern, characteristics and incidence rate of injuries in futsal, this study was designed to record and analyze the injuries in Iran futsal national teams.

\section{Objectives}

These findings could be beneficial for educational and preventive efforts to protect futsalers' health in this country and also at the international level.

\section{Patients and Methods}

This prospective cohort study includes all Iranian futsal players (17 players of women's team, 23 players of men's team, and 15 players of U-23 men's team) who were invited to national team camps from March 2011 to September 2012. Prior to the start of study, all 55 players participated in the Pre-competition Medical Assessment (PCMA) based on the FIFA protocol (15). At the beginning of the study

Copyright ( 2014, Kowsar Corp.; Published by Kowsar. This is an open-access article distributed under the terms of the Creative Commons Attribution-NonCommercial 4.0 International License (http://creativecommons.org/licenses/by-nc/4.0/) which permits copy and redistribute the material just in noncommercial usages, provided the original work is properly cited. 
all 55 futsal players (17 females and 38 males) were interviewed and their demographic data including age, BMI (Body Mass Index), years of playing in the premier futsal league, and average time of training per week were collected. All players were asked to sign a consent letter for the study. They were followed in national team camps for about 18 months. In this period, all injuries sustained by the subjects during the matches and also training sessions were recorded. In addition, match and training exposure times were recorded for all the subjects during the study period. Exposure times were obtained by the special exposure report form. The players' exposures were categorized into 2 time spans: 1-training period; 2- matches' period. During the two periods, regular face-to-face contacts were conducted to all the subjects by their team physicians to record their injuries and complaints. Whenever a subject incurred an injury, a sports medicine physician reevaluated his/her condition and in a standard form. The characteristics of each injury including type, location, cause and time of injury and also duration of absence from the match or training (in days) was recorded. In this study, both the injury definition and the procedure of the recording of the player's injuries were compliant with the international consensus statement for the epidemiological studies of injuries in football (16). In this regard, injury was defined as "any physical complaint sustained by a futsal player that results from a football match or career related training sessions, irrespective of the need for medical attention or time loss from football activities". Also, in this study the medical complaints of the futsal players were recorded. In this regard, all team physicians were also asked to record any gradual-onset injury not attributable to any recognized event. In this study, the severity of injury was classified based on players' period of absence from playing into four categories of: slight (0-3 days), mild (4 to 7 days), moderate (8 to 30 days), and severe (more than 30 days) (17). This study was approved by the Ethics Committee of the Iran University of Medical Sciences. The incidence rate of injury was indicated as the number of injuries per 1000 player-hours of exposure (sum of the training and match hours). Data were analyzed using statistical software SPSS 16.0.0. (SPSS Inc. Chicago, IL, USA).

\section{Results}

This study included 55 Iranian national futsal players. Baseline characteristics of the study participants are presented in Table 1. The total exposure time of all players was 24326 hours (21138 hours during training and 3188 hours during matches). In total 54 injuries sustained by 32 players were reported (incidence rate $=2.22$ injuries per 1000 players-hours). The incidence rate of injury was significantly higher in female players than male players and U-23 men's players $(\mathrm{P}=0.001$ and $\mathrm{P}<0.001$, respectively; Table 2 ). This difference seems to be mostly due to training sessions since when it comes to match periods, no significant differences in the incidence rate of injuries between the groups was found (Table 2). Our data showed that the incidence rate of injury during match hours was significantly more than training sessions (6.27 vs. 1.61 injuries per 1000 player-hours, $\mathrm{P}=0.001)$. The majority of incurred injuries were due to non-contact trauma. The incidence rate of non-contact injuries was significantly higher in female players compared to the male players $(\mathrm{P}=0.02$, Table 2$)$. The ankle (40.7\%) was the most frequent site of injury, followed by knee (22.2\%) and groin (13\%) (Table 3). Regarding the type of injuries, it was found that sprain; strain and lesion of meniscus or cartilage were the most frequent types of injury in Iranian national futsal players (Table 2).

\begin{tabular}{|c|c|c|c|c|c|c|}
\hline & \multirow[t]{2}{*}{ Women's Team $(\mathbf{n}=17)$} & \multicolumn{3}{|c|}{ Men's Teams } & \multirow[t]{2}{*}{ Total $(n=55)$} & \multirow[t]{2}{*}{ PValue } \\
\hline & & U-23 Men's Team $(n=15)$ & Men's Team $(n=23)$ & Total $(n=38)$ & & \\
\hline Age, $y$ & & & & & & 0.7 \\
\hline Mean \pm SD & $25.00 \pm 3.18$ & $21.47 \pm 1.12$ & $26.61 \pm 3.71$ & $24.58 \pm 3.89$ & $24.71 \pm 3.66$ & \\
\hline Median & 25 & 22 & 25 & 24 & 24 & \\
\hline Range & $20-31$ & $20-23$ & $22-36$ & $20-36$ & $20-36$ & \\
\hline Weight, kg & & & & & & $<0.0001$ \\
\hline Mean \pm SD & $54.6 \pm 5.7$ & $70.3 \pm 6.5$ & $75.1 \pm 6.9$ & $73.2 \pm 7.0$ & $67.3 \pm 10.9$ & \\
\hline Median & 54 & 73.2 & 74.6 & 74.2 & 69.1 & \\
\hline Range & $43.2-68.0$ & $61.5-81.0$ & $62.4-94.8$ & $61.5-94.8$ & $43.2-94.8$ & \\
\hline Height, m & & & & & & $<0.0001$ \\
\hline Mean \pm SD & $1.6 \pm 0.04$ & $1.7 \pm 0.1$ & $1.8 \pm 0.05$ & $1.7 \pm 0.05$ & $1.7 \pm 0.1$ & \\
\hline Median & 1.6 & 1.74 & 1.8 & 1.8 & 1.7 & \\
\hline Range & $1.5-1.7$ & 1.6-1.8 & $1.6-1.9$ & 1.6-1.9 & $1.5-1.9$ & \\
\hline BMI, $\mathrm{kg} / \mathrm{m}^{2}$ & & & & & & $<0.0001$ \\
\hline Mean \pm SD & $20.4 \pm 1.4$ & $23.2 \pm 1.4$ & $24.3 \pm 1.5$ & $23.8 \pm 1.5$ & $22.7 \pm 2.2$ & \\
\hline Median & 20.3 & 23.4 & 24.2 & 23.74 & 23.0 & \\
\hline Range & $18.7-24.2$ & $20.4-25.4$ & $21.7-27.7$ & $20.4-27.7$ & $18.7-27.7$ & \\
\hline Fat, \% & & & & & & $<0.0001$ \\
\hline Mean \pm SD & $21.2 \pm 3.5$ & $10.9 \pm 1.8$ & $14.4 \pm 3.1$ & $13.0 \pm 3.2$ & $15.5 \pm 5.0$ & \\
\hline Median & 20.1 & 11 & 13.6 & 12.9 & 15.3 & \\
\hline Range & $15.7-27.8$ & $8.2-14.5$ & 8.4-20.1 & $8.2-20.1$ & $8.2-27.8$ & \\
\hline
\end{tabular}


Angoorani Het al.

Table 2. Comparison of Injuries Among Iranian National Futsal Teams ${ }^{\text {a }}$

\begin{tabular}{|c|c|c|c|c|c|c|c|c|c|c|c|}
\hline & \multirow{2}{*}{\multicolumn{2}{|c|}{ Women's Team }} & \multicolumn{6}{|c|}{ Men's Teams } & \multirow{2}{*}{\multicolumn{2}{|c|}{ Total Injuries }} & \multirow[t]{3}{*}{ PValue } \\
\hline & & & \multicolumn{2}{|c|}{ U-23 Men's } & \multicolumn{2}{|c|}{ Men's Team } & \multicolumn{2}{|c|}{ Total $^{b}$} & & & \\
\hline & No. & $\mathbf{I R}^{\mathrm{d}}$ & No. & IR & No. & IR & No. & IR & No. & IR & \\
\hline Number of injuries $\mathrm{e}$ & 28 & 4.17 & 8 & 0.90 & 18 & 2.07 & 26 & 1.48 & 54 & 2.22 & 0.001 \\
\hline \multicolumn{12}{|l|}{ Location of injury } \\
\hline Head and trunk & 3 & 0.45 & 1 & 0.11 & 1 & 0.12 & 2 & 0.11 & $5(9.3)$ & 0.21 & 0.2 \\
\hline Upper extremity & 2 & 0.30 & 0 & 0 & 1 & 0.12 & 1 & 0.06 & $3(5.6)$ & 0.12 & 0.3 \\
\hline Lower extremity & 23 & 3.43 & 7 & 0.78 & 16 & 1.84 & 23 & 1.31 & $46(85.2)$ & 1.89 & 0.01 \\
\hline Groin & 4 & 0.60 & 1 & 0.11 & 2 & 0.23 & 3 & 0.17 & $7(13.0)$ & 0.29 & 0.2 \\
\hline Thigh & 0 & 0 & 2 & 0.22 & 1 & 0.12 & 3 & 0.17 & $3(5.56)$ & 0.12 & 0.08 \\
\hline Knee & 5 & 0.74 & 1 & 0.11 & 6 & 0.69 & 7 & 0.40 & $12(22.2)$ & 0.49 & 0.3 \\
\hline Lower Leg & 1 & 0.15 & 0 & 0 & 0 & 0 & 0 & 0 & $1(1.8)$ & 0.04 & 0.3 \\
\hline Achilles tendon & 1 & 0.15 & 0 & 0 & 0 & 0 & 0 & 0 & $1(1.8)$ & 0.04 & 0.3 \\
\hline Ankle & 12 & 1.79 & 3 & 0.34 & 7 & 0.81 & 10 & 0.57 & $22(40.7)$ & 0.9 & 0.03 \\
\hline \multicolumn{12}{|l|}{ Type of injury } \\
\hline Concussion & 1 & 0.15 & 0 & 0 & 1 & 0.12 & 1 & 0.06 & $2(3.7)$ & 0.08 & 0.6 \\
\hline Fracture & 1 & 0.15 & 0 & 0 & 0 & 0 & 0 & 0 & $1(1.8)$ & 0.04 & 0.3 \\
\hline Stress fracture & 1 & 0.15 & 0 & 0 & 0 & 0 & 0 & 0 & $1(1.8)$ & 0.04 & 0.3 \\
\hline Tendon rupture & 1 & 0.15 & 0 & 0 & 0 & 0 & 0 & 0 & $1(1.8)$ & 0.04 & 0.3 \\
\hline Lig. rupture & 2 & 0.3 & 1 & 0.11 & 1 & 0.12 & 2 & 0.11 & $4(7.4)$ & 0.16 & 0.4 \\
\hline Sprain & 16 & 2.38 & 4 & 0.45 & 8 & 0.92 & 12 & 0.68 & $28(51.8)$ & 1.15 & 0.01 \\
\hline $\begin{array}{l}\text { Meniscus or carti- } \\
\text { lage }\end{array}$ & 2 & 0.30 & 0 & 0 & 5 & 0.58 & 5 & 0.28 & $7(13.0)$ & 0.29 & 0.9 \\
\hline Strain & 2 & 0.30 & 2 & 0.22 & 3 & 0.35 & 5 & 0.28 & $7(13.0)$ & 0.29 & 0.9 \\
\hline $\begin{array}{l}\text { Contusion, hem, } \\
\text { bruise }\end{array}$ & 1 & 0.15 & 0 & 0 & 0 & 0 & 0 & 0 & $1(1.8)$ & 0.04 & 0.3 \\
\hline $\begin{array}{l}\text { Muscle cramps/ } \\
\text { spasm }\end{array}$ & 0 & 0 & 1 & 0.11 & 0 & 0 & 1 & 0.06 & $1(1.8)$ & 0.04 & 0.3 \\
\hline \multicolumn{12}{|l|}{ Cause of injury } \\
\hline Overuse & 3 & 0.45 & 0 & 0 & 0 & 0 & 0 & 0 & $3(5.6)$ & 0.12 & 0.08 \\
\hline Non-contact trauma & 18 & 2.68 & 5 & 0.56 & 15 & 1.73 & 20 & 1.14 & $38(70.4)$ & 1.56 & 0.02 \\
\hline Contact $^{\mathrm{f}}$ & 7 & 1.04 & 3 & 0.34 & 3 & 0.35 & 6 & 0.34 & $13(24.1)$ & 0.53 & 0.09 \\
\hline \multicolumn{12}{|l|}{ Time of injury } \\
\hline In training hours & 18 & 3.11 & 3 & 0.37 & 13 & 1.79 & 16 & 1.04 & $34(63.0)$ & 1.61 & 0.01 \\
\hline In match hours & 10 & 10.75 & 5 & 6.10 & 5 & 3.48 & 10 & 4.43 & $20(37.0)$ & 6.27 & 0.09 \\
\hline First half & 5 & - & 2 & - & 1 & - & 3 & - & $8(40)$ & - & - \\
\hline Second half & 5 & - & 3 & - & 4 & - & 7 & - & $12(60)$ & - & - \\
\hline \multicolumn{12}{|l|}{ Duration of absence } \\
\hline 1-3 days & 11 & 1.64 & 2 & 0.22 & 5 & 0.58 & 7 & 0.4 & $18(33.3)$ & 0.74 & 0.02 \\
\hline 4-7 days & 9 & 1.34 & 3 & 0.34 & 9 & 1.04 & 12 & 0.68 & $21(38.9)$ & 0.86 & 0.2 \\
\hline 8-28 days & 5 & 0.74 & 2 & 0.22 & 1 & 0.12 & 3 & 0.17 & $8(14.8)$ & 0.33 & 0.1 \\
\hline$>28$ days & 3 & 0.45 & 1 & 0.11 & 3 & 0.35 & 4 & 0.23 & $7(13.0)$ & 0.29 & 0.4 \\
\hline
\end{tabular}

a Abbreviation: Lig, Ligamentous; hem, hematoma; IR, incidence rate.

$\mathrm{b}$ Total male players.

${ }^{\mathrm{C}} \mathrm{P}$ value for the comparison of incidence rates of variables between male and female players.

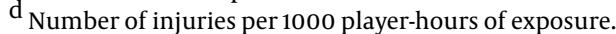

${ }^{e}$ Number of injuries during training or matches which caused at least one day of absence.

$\mathrm{f}_{\text {Contact trauma with another player. }}$ 
Angoorani Het al.

\begin{tabular}{|c|c|c|c|c|c|}
\hline \multirow[t]{2}{*}{ Type and Location } & \multicolumn{5}{|c|}{ Injury Severity ${ }^{\mathrm{b}}$} \\
\hline & Slight & Minor & Moderate & Severe & Total \\
\hline Sprain (joints or ligaments injuries) & $9(0.37)$ & $14(0.58)$ & $5(0.21)$ & 0 & $28(1.15)$ \\
\hline Ankle & $5(0.21)$ & $13(0.53)$ & $4(0.16)$ & 0 & $22(0.90)$ \\
\hline Other & $4(0.16)$ & $1(0.04)$ & $1(0.04)$ & 0 & $6(0.25)$ \\
\hline Strain & $5(0.21)$ & $2(0.08)$ & 0 & 0 & $7(0.29)$ \\
\hline Groin & $3(0.12)$ & $2(0.08)$ & 0 & 0 & $5(0.21)$ \\
\hline Other & $2(0.08)$ & 0 & 0 & 0 & $2(0.08)$ \\
\hline Lesion of meniscus or cartilage (knee) & $2(0.08)$ & $2(0.08)$ & $1(0.04)$ & $2(0.08)$ & $7(0.29)$ \\
\hline Ligamentous rupture of Knee & 0 & 0 & 0 & $4(0.16)$ & $4(0.16)$ \\
\hline Other injuries ${ }^{c}$ & $2(0.08)$ & $3(0.12)$ & $2(0.08)$ & $1(0.04)$ & $8(0.33)$ \\
\hline Total & $18(0.74)$ & $21(0.86)$ & $8(0.33)$ & $7(0.29)$ & $54(2.22)$ \\
\hline
\end{tabular}

\section{Discussion}

This prospective study is one of few surveys which examines the incidence and characteristics of injuries in top-level futsal players and to our knowledge, is the first one in Asia. According to our findings the incidence rate of injury among futsal players was 2.22 injuries per 1000 players-hours. This finding is in contrast with the study by Junge and Dvorak (4) which reported 195.6 injuries per 1000 players-hours and also the reported incidence rate of injury in the FIFA World Cups 1998, 2002 and 2006 (mean incidence rate of 74.2 injuries per 1000 playershours) $(4,7,12)$. This difference might be due to the different level of playing futsal in the FIFA World Cups and Iranian futsal league, besides, in these studies only the injuries incurred during the matches were recorded while we reported all injuries that happened in the matches and training sessions. A major obstacle in the evaluation of the incidence and characteristics of injuries in futsal is that there is no specific consensus for the definition of injuries among futsal players, while standard protocols have been developed for footballers (18-21). In previous studies, consecutive absence from training or match has been used as the definition of injury (19). However, by use of this definition, many chronic and mild injuries will be missed $(20,21)$. In this study, we used the definition which was developed by Fuller et al. for footballers (16). On this basis injury defined as any physical complaint that results from a career related training session or a match, irrespective of the need for medical attention or time loss from sports activities $(4,21)$. So, in addition to limited number of studies regarding the injury characteristics among futsal players, comparison between the studies due to the use of different definitions is not possible. This study is one of the very few surveys which compares the incidence and characteristics of injuries between men and women in the top-level futsal players. The results show that the rate of injury is higher in female players than male players $(P=0.001$, Table 2$)$. As it is mentioned before, this significant difference was mostly due to non-contact injuries. The level of fitness of the players is one of the important factors which is highly associated with the risk of sports injuries $(11,20)$. Considering the nature of futsal which requires multiple sprints and frequent changes in the direction of movements, the physical fitness factors (particularly speed and agility) of the athletes should be much improved to make the players able to participate in the competitions. Therefore, it seems rational that rate of injury among female futsal players with lower level of physical fitness than men is much more than male futsal players, as is shown in this study $(6,12,22)$. While Junge and Dvorak reported that the majority of injuries in Futsal World Cups were caused by contact trauma (4), the majority of injuries sustained by the athletes in the current study were due to non-contact trauma. Inclusion of injuries which occurred during training sessions might be considered as a possible explanation for this difference. In the present study, $85.2 \%$ injuries were located at the lower extremities with the ankle being the most frequent location of injury (40.7\%). These results are similar to the results that were reported previously for elite football male players $(4,6,22)$. Also, in the study of Junge and Dvorak (4) the majority of injuries in futsal were observed at the lower extremity, and the most frequent diagnoses were contusions of the lower leg and ankle sprain. Serrano and colleagues (23) showed that the sprain of the tibial-tarsal joint was the most common part of injury in Futsal (48.8\% of total) which is in accordance 
with the results of our study. As the most important limiting factor in this study, we had to let some players leave the national team camp for some periods to play for their own team in the futsal league. However, whenever they came back to national team camp, the team physicians reexamined them and they recorded every new observed injury. Considering the growing popularity of futsal, further studies in order to evaluate the incidence, characteristics, and cause of injuries in futsal are required (24-26). Such studies could be the cornerstone for development of injury-prevention programs, based on the FIFA 11+ prevention program. The incidence of injury in futsal is high and female players in comparison with male players are more prone to be injured especially by non-contact trauma. The ankle is the most frequent part of injury followed by the knee and the groin in all futsal players. In addition, sprain is the most frequent type of injury among Iranian futsal players. More information on injury mechanisms in futsal is needed to develop specific injury-preventive strategies.

\section{Acknowledgements}

This research was funded by Iran University of Medical Sciences in cooperation with Medical committee of Iran Football Federation. The authors highly appreciate the cooperation of all team physicians who collected the data for this project. Also we wish to thank, Astrid Junge and Prof. Jiri Dvorak for their kind advice in editing the paper, and Mostafa Zarei for his extensive data collection efforts during this study.

\section{Authors' Contributions}

Hooman Angoorani: Concept/Design, Acquisition of Data, Data Analysis/Interpretation, Manuscript Preparation, Critical Revision of the Manuscript, Funds Collection, Approval of the Article; Zohreh Haratian: Concept/ Design, Acquisition of Data, Data Analysis/Interpretation, Manuscript Preparation, Approval of the Article; Ali Mazaherinezhad: Manuscript Preparation, Critical Revision of the Manuscript, Approval of the Article; Shima Younespour: Concept/Design, Acquisition of Data, Data Analysis/Interpretation, Manuscript Preparation.

\section{Funding/Support}

This research was funded by Iran University of Medical Sciences in cooperation with Medical committee of Iran Football Federation.

\section{References}

1. Sub-Committee of the International Football Association Board.. Futsal laws of the game. Switzerland: Federation Internationale de Football Association; 2011. Available from: http://www.fifa. $\mathrm{com} / \mathrm{mm} /$ document/fifafacts/bcoffsurv/bigcount.summaryreport_7022.pdf.
2. Schmikli SL, Backx FJ, Kemler HJ, van Mechelen W. National survey on sports injuries in the Netherlands: target populations for sports injury prevention programs. Clin J Sport Med. 2009;19(2):101-6.

3. Cain LE, Nicholson LL, Adams RD, Burns J. Foot morphology and foot/ankle injury in indoor football. J Sci Med Sport. 2007; 10(5):311-9.

4. Junge A, Dvorak J. Injury risk of playing football in Futsal World Cups. BrJSports Med. 2010;44(15):1089-92.

5. Lindenfeld TN, Schmitt DJ, Hendy MP, Mangine RE, Noyes FR. Incidence of injury in indoor soccer. Am J Sports Med. 1994;22(3):364-71.

6. Junge A, Dvorak J. Soccer injuries: a review on incidence and prevention. Sports Med. 2004;34(13):929-38.

7. Junge A, Dvorak J, Graf-Baumann T, Peterson L. Football injuries during FIFA tournaments and the Olympic Games, 1998-2001: development and implementation of an injury-reporting system. Am J Sports Med. 2004;32(1Suppl):80S-9S.

8. Junge A, Dvorak J. Injuries in female football players in top-level international tournaments. Br J Sports Med. 2007;41 Suppl 1:i3-7.

9. Junge A, Dvorak J, Graf-Baumann T. Football injuries during the World Cup 2002. Am J Sports Med. 2004;32(1 Suppl):23S-7S.

10. Fuller CW, Junge A, Dvorak J. A six year prospective study of the incidence and causes of head and neck injuries in international football. Br J Sports Med. 2005;39 Suppl 1:i3-9.

11. Emery CA, Meeuwisse WH. The effectiveness of a neuromuscular prevention strategy to reduce injuries in youth soccer: a clusterrandomised controlled trial. Br J Sports Med. 2010;44(8):555-62.

12. Dvorak J, Junge A, Grimm K, Kirkendall D. Medical report from the 2006 FIFA World Cup Germany. Br J Sports Med. 2007;41(9):578-81.

13. Andreasen I, Fauno P, Lund B. Football injuries among youth. Scand J Med Sci Sports. 1993;3(1):62-6.

14. Castagna C, D'Ottavio S, Granda Vera J, Barbero Alvarez JC. Match demands of professional Futsal: a case study. J Sci Med Sport. 2009;12(4):490-4.

15. Dvorak, J., Ackerman, K. E., International Federation of Association Football Medical Assessment and Research Centre, . Football Medicine Manual .Switzerland: Fédération Internationale de Football Association; 2009.

16. Fuller CW, Ekstrand J, Junge A, Andersen TE, Bahr R, Dvorak J, et al. Consensus statement on injury definitions and data collection procedures in studies of football (soccer) injuries. BrJ Sports Med. 2006;40(3):193-201.

17. Yoon YS, Chai M, Shin DW. Football injuries at Asian tournaments. Am J Sports Med. 2004;32(1 Suppl):36S-42S.

18. Finch CF. An overview of some definitional issues for sports injury surveillance. Sports Med.1997;24(3):157-63.

19. Junge A, Dvorak J. Influence of definition and data collection on the incidence of injuries in football. Am J Sports Med. 2000;28(5 Suppl):S40-6.

20. van Mechelen W, Hlobil H, Kemper HC. Incidence, severity, aetiology and prevention of sports injuries. A review of concepts. Sports Med.1992;14(2):82-99.

21. Junge A, Cheung K, Edwards T, Dvorak J. Injuries in youth amateur soccer and rugby players-comparison of incidence and characteristics. BrJ Sports Med. 2004;38(2):168-72.

22. Giza E, Micheli LJ. Soccer injuries. Med Sport Sci. 2005;49:140-69.

23. Serrano J, Shahidian S, Voser R. Incidence and injury risk factors in Portuguese futsal players. Rev Bras Med Esporte. 2013; 19(2):123-9.

24. Ekstrand J, Timpka T, Hagglund M. Risk of injury in elite football played on artificial turf versus natural grass: a prospective twocohort study. BrJ Sports Med. 2006;40(12):975-80.

25. Fuller CW, Smith GL, Junge A, Dvorak J. The influence of tackle parameters on the propensity for injury in international football. Am J Sports Med. 2004;32(1 Suppl):43S-53S.

26. Andersen TE, Larsen O, Tenga A, Engebretsen L, Bahr R. Football incident analysis: a new video based method to describe injury mechanisms in professional football. $\mathrm{Br} J$ Sports Med. 2003;37(3):226-32. 